BULLETIN Bulletin hispanique

HISPANIQUE Université Michel de Montaigne Bordeaux

$122-2 \mid 2020$

L'épithalame en Espagne

\title{
Scènes de la traduction France-Argentine
}

Paris : Rue d'Ulm / Presses de l'École normale supérieure

\section{Robin Lefere}

\section{(2) OpenEdition}

Journals

Édition électronique

URL : http://journals.openedition.org/bulletinhispanique/11958

DOI : 10.4000/bulletinhispanique. 11958

ISBN : $1775-3821$

ISSN : $1775-3821$

Éditeur

Presses universitaires de Bordeaux

\section{Édition imprimée}

Date de publication : 20 décembre 2020

Pagination : 779-781

ISBN : 979-10-300-0606-3

ISSN : 0007-4640

\section{Référence électronique}

Robin Lefere, "Scènes de la traduction France-Argentine », Bulletin hispanique [En ligne], 122-2 | 2020, mis en ligne le 14 décembre 2020, consulté le 19 janvier 2021. URL : http://journals.openedition.org/ bulletinhispanique/11958; DOI : https://doi.org/10.4000/bulletinhispanique.11958

Ce document a été généré automatiquement le 19 janvier 2021.

Tous droits réservés 


\title{
Scènes de la traduction France- Argentine
}

\author{
Paris : Rue d'Ulm / Presses de l'École normale supérieure
}

Robin Lefere

\section{RÉFÉRENCE}

Scènes de la traduction France-Argentine, sous la direction de Roland BÉHAR et Gersende CAMENEN. - Paris : Rue d'Ulm / Presses de l'École normale supérieure, 2020, 277 pages.

1 Ce livre, qui propose 13 articles d'autant de contributeurs, s'ouvre sur une excellente introduction des deux directeurs de la publication, Roland Béhar et Gersende Camenen. En une douzaine de pages aussi denses que claires, riches en informations et en références multiples, le sujet est parfaitement posé, la scène dressée : l'espace à la fois physique, littéraire et imaginaire où au fil des deux derniers siècles s'est progressivement construit un "dialogue au long cours", nourri d'admirations personnelles et d'émulation, de complicités intellectuelles et d'amitiés.

2 La « scène » est cependant plus qu'un espace ; la notion évoque la mise en scène et ainsi la représentation : celle que l'on se fait de soi et de l'autre, de soi à travers l'autre, entre curiosité passionnée, exotisme et narcissisme. Dans ce jeu de miroirs et d'espejismos, la traduction joue un rôle fondamental, non seulement en tant que médiation fonctionnelle, mais par tous les questionnements identitaires lato sensu qu'implique ce processus de transcodage culturel et linguistique.

3 Il s'agit donc ici d'histoire littéraire et culturelle (avec tous les relais de celle-ci), d'histoire des représentations (avec une dimension imagologique), mais aussi d'histoire de la traduction, abordée dans sa triple composante : interpersonnelle, institutionnelle, réflexive (voire théorique). L'accent est mis sur les acteurs -écrivains, traducteurs, éditeurs, critiques, " passeurs » en général-, dont certaines figures extraordinaires qui cumulèrent tous les rôles (telle Victoria Ocampo). Cette histoire est certes asymétrique : l'élite argentine fut francophile dès le dix-neuvième siècle (songeons à 
Sarmiento), et au vingtième cette francophilie brilla de tous ses feux grâce à la fameuse Sur et à sa fondatrice et directrice (qui de plus écrivit principalement en français, et se fit traduire en espagnol), tandis que la France ne s'est véritablement intéressée à la culture argentine qu'à partir des années 1950. Borges et Caillois furent décisifs, sans doute, et le «boom» des années 60, mais le terrain avait été préparé par des Valéry Larbaud ou Marcel Bataillon, et fut par la suite considérablement enrichi par ces gobetween que sont les exilés (de Cortázar à Bianciotti, en passant par J.J. Saer, Mario Goloboff et un long et caetera).

4 C'est dans ce cadre que s'inscrivent les articles de M. Cámpora, A. Gasquet, V. Liendo, A. Louis, A. Valdés-Zamora, S. Molloy, M. Sverdloff, M. Di Ció, V. Litvan, G. Camenen, ainsi que les témoignages d'expérience traductrice de S. Baron Supervielle, A. Bensoussan, D. Coste. Ces treize contributions -huit en français, cinq en espagnol, faisant ainsi pratiquer activement l'entre-deux- forment un ensemble remarquablement homogène, tout en étant contrasté et pertinemment distribué en cinq sections qui illustrent la diversité de la matière («Imaginaires de la langue, bilinguisme et traduction »; «Sur, un pôle d'attraction"; "Retraductions et relectures argentines contemporaines", "Traduit de l'argentin », «La voix des traducteurs »). Il y a des noms et des titres qui sont nécessairement récurrents, mais les éclairages sont agréablement complémentaires; les directeurs ont composé leur volume en prenant soin d'éviter aussi bien les ruptures que les redondances. Au fil des pages, se reconstitue de façon très suggestive tout un petit monde: les noms, certains familiers et d'autres moins, prennent place dans des configurations et des réseaux parfaitement mis en évidence. On retrouve ainsi, en contextes et en échanges, les Ocampo (Victoria mais aussi Silvina), les Caillois (Roger et Yvette), les Berman (Antoine et Isabelle), les Gálvez (Delfina Bunge et Manuel), les Supervielle... Sont aussi retracés les rapports multiples entre les revues Sur et Orígenes -dont les (non)positionnements auraient été influencés par La trahison des clercs de Benda-, et d'autre part la NRF, ou la Revista de Occidente de Ortega y Gasset. On voit encore comment Lettres françaises, fille de Sur, constitue une préfiguration de «La Croix du Sud». D'un point de vue plus technique, on apprécie comment les choix linguistiques et les évaluations esthétiques sont conditionnés par les réflexions sur l'argentin et l'argentinité ; que ce soit à l'occasion d'une polémique entre Juan José Saer et Héctor Bianciotti autour de la figure et de la traduction de Robert Arlt, ou à partir de la question du choix de l'espagnol dans lequel traduire: un espagnol argentin voire argentinisé, un espagnol péninsulaire, ou encore un espagnol artificiellement global ? Se discutent aussi des aspects éditoriaux, en particulier, dans quelle mesure convient-il d'attirer l'attention du public sur l'opération de traduction, voire de théoriser et d'expliciter les options du traducteur, comme c'est le cas -radicaldans une collection académique telle Colihue Clásica? Certains auteurs posent des problèmes spécifiques du fait qu'ils jouent sur l'entre-deux culturel et linguistique : ainsi Jules Supervielle qui profite de son parfait bilinguisme et de sa double culture pour "voir un peu du dehors " et construire une œuvre à double lecture comme L'homme de la pampa, ou Juan Gelman qui décentre et recentre son écriture en écrivant ou réécrivant en ladino, langue de l'exil, avant de se traduire lui-même en un espagnol volontiers archaïsant.

5 Ce volume propose donc une belle invitation aux voyages (philologiques et autres), qui pourrait en inspirer d'autres: de telles «scènes de la traduction» seraient 
probablement tout aussi fécondes -au-delà du cas évident de Borges- si elles mettaient en rapport l'Argentine et l'Angleterre, voire l'Argentine et les USA.

\section{AUTEURS}

\section{ROBIN LEFERE}

Université libre de Bruxelles 